\title{
LXXIV. On an alleged demonstration of Fresnel relative to the wave-surface in the theory of double refraction
}

John Tovey Esq.

To cite this article: John Tovey Esq. (1837) LXXIV. On an alleged demonstration of Fresnel relative to the wave-surface in the theory of double refraction, Philosophical Magazine Series 3, 11:70, 524-524, DOI: 10.1080/14786443708649344

To link to this article: http://dx.doi.org/10.1080/14786443708649344

曲 Published online: 01 Jun 2009.

Submit your article to this journal $[\pi$

Џll Article views: 2

Q View related articles $\sqsubset$ 


\section{$\left[\begin{array}{lll}524 & ]\end{array}\right.$}

LXXIV. On an alleged Demonstration of Fresnel relative to the Wave-surface in the Theory of Double Refraction. By John Tovey, Esq.

To the Editors of the Philosophical Magazine and Journal. Gentlemen,

A M glad to find from Mr. Lubbock's paper in your last Number, p. 417, that he is devoting a portion of his mathematical talents to physical optics. His comparison of Fresnel's ideas with those which have been since developed by M. Cauchy and others, is, in the present state of the science, of great importance. I hope he will continue these investigations; and I beg that you will allow me, through the medium of your Journal, to solicit his consideration of that part of Fresnel's theory in which it is supposed to be proved that when the axes of elasticity are taken for the coordinate axes, the differential equations may be reduced to the form

$$
\frac{\mathrm{d}^{2} \xi}{\mathrm{d} t^{2}}=m \mathbf{x}\left\{\Phi(r)+\psi(r) \Delta x^{\mathrm{q}}\right\} \Delta \xi .
$$

Mr. Lubbock takes this point for granted, referring for a proof of it to the remarks of Fresnel in the Mém. de l' Institut. To these remarks I have no access; but I conceive that they can be no more than equivalent to the demonstration of $\mathbf{C}$. J. in your last volume, p. 24, which only proves, that if one molecule alone of the system be displaced, it is always possible so to take the axes of the coordinates that the differential equattions may be reduced to the form

$$
\frac{\mathrm{d}^{2} \xi}{\mathrm{d} t^{8}}=\Delta \xi \cdot m \Sigma\left\{\phi(r)+\psi(r) \Delta x^{2}\right\} .
$$

Now this equation is inapplicable when the system is in a state of undulation; and, therefore, unless it can be proved that it may then be changed into the form made use of by Mr. Lubbock, Fresnel's demonstration must be abandoned.

Littlemoor, near Clitheroe, I am, Gentlemen, yours, \&c. Nov. $6,1837$.

LXXV. A Report of the Progress of Vegetable Physiology during the Year 1836. By J. Meyen, Professor of Botany in the University of Berlin.**

[Continued from p. 446.]

On the Structure and Function of Spiral Tubes.

THAT the spiral tubes in vegetables serve to conduct the nutritive sap has once more been remarked by Link $\dagger$, in

* From Wiegmann's Arckiv für Vaturgeschichte, 1837, Part 3. Translated by Mr. Wni. Francis. † Plilos. Bot., p. 189. 